\section{Carotid shudder as a sign of ascending aorta dissection}

A coarse shudder in the carotid arterial pulse is sometimes associated with aortic cusp rupture, but it is not described as a physical sign of dissection of the ascending aorta in standard cardiological textbooks. ${ }^{1-4}$ We report its presence in two cases of dissecting aneurysm, in one of which it was of diagnostic value.

\section{Case reports}

A previously well 28 -year-old man was admitted with severe central chest pain to the Royal Devon and Exeter Hospital under the care of Dr D B Shaw. Significantly, his mother had died of a ruptured aorta. He had florid skeletal stigmata of Marfan's syndrome. There were signs of free aortic regurgitation but none, either clinical or electrocardiographic, of left ventricular hypertrophy, suggesting that the lesion was acute. There was no evidence of myocardial infarction. Chest $x$-ray examination showed no mediastinal widening, but clearly dissection of the aorta at its root had occurred. The patient was transferred to the Wessex Regional Cardiac Centre, where, in addition to the above findings, a coarse shudder in the carotid arterial pulse was noted. Angiography showed the dissection and severe aortic regurgitation, and a free moving edge of torn media and intima was seen as a linear shadow within the ascending aorta. At operation (Mr J M Monro) the ascending aorta was replaced by a Dacron prosthesis and the aortic valve by a Bjork Shiley prosthetic valve. Postoperative recovery was uneventful.

In the second case, seen only two days after the first, the patient, a 51-yearold man, had attended outpatients with mild angina three years previously. His physical signs were therefore documented. The day before admission he had had transient central chest pain. This recurred more severely the next morning. By admission to the Wessex Regional Cardiac Centre with a provisional diagnosis of myocardial infarction, despite a normal electrocardiogram, he was hypotensive but there were no abnormal signs in the heart and, in particular, no evidence of aortic regurgitation. A coarse shudder was felt in the carotid pulse, however, and, remarkably, it varied in intensity. Although the mediastinal width in an $x$-ray film taken by a portable machine was within normal limits, the diagnosis of dissection seemed likely, and, with the experience of the first patient freshly in mind, the carotid shudder suggested that it was the ascending aorta. Since the aortic valve was not affected conservative measures were adopted, but next day signs of severe aortic regurgitation appeared. Angiography confirmed dissection of the ascending aorta and aortic reflux. Although unsuspected clinically, the aortic root had the typical pear-shaped Marfan configuration. On this occasion the free mobile edge of the dissected aortic wall was captured on cut films (fig). At operation (Mr J K Ross) aortic valve and ascending aortic replacement were performed as in case 1 . Postoperative recovery was uneventful.

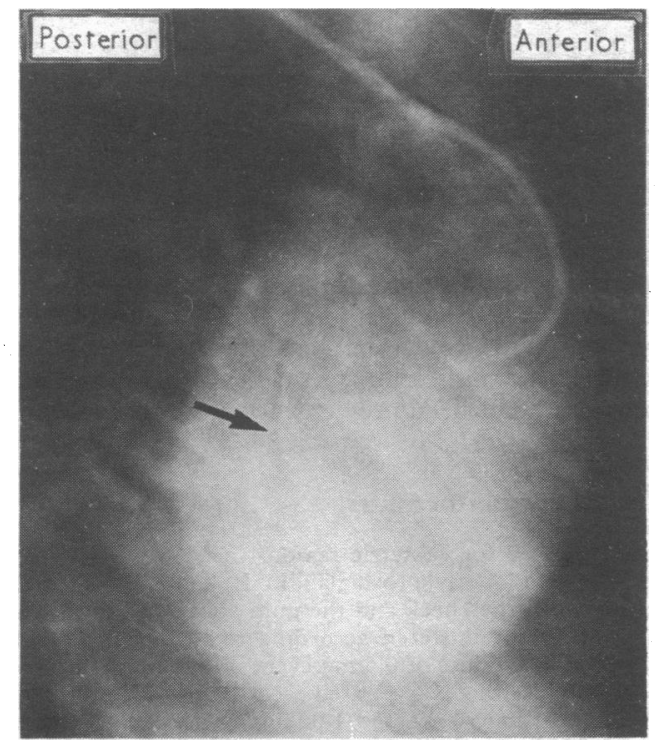

Lateral aortogram. Whole of structure shown is aneurysmal ascending aorta (with aortic valve at foot of picture). Arrow points to free edge of dissection. Both true and false lumens have filled well at this stage.

\section{Discussion}

Carotid shudder as a sign of ascending aortic dissection may not be widely recognised, but a vibration in either sternoclavicular joint was described by Logue and Sykes ${ }^{5}$ and may represent the same phenomenon. It is probably due to partial obstruction by free tissue within the aortic root, for although systolic shudders and thrills are sometimes found in free aortic regurgitation from any cause, the varying shudder before aortic regurgitation in our second patient cannot be explained in any other way. Most dissections are readily diagnosed, but when chest $x$-ray examination is unhelpful, as in both our cases, palpation of the carotid pulse may afford a valuable clue to the correct diagnosis.

We thank Dr D B Shaw for permission to report case 1, and Mr J K Ross and $\mathrm{Mr} \mathrm{J} \mathrm{M}$ Monro for the operative details.

1 Friedberg, C K, Diseases of the Heart, 3rd edn. Philadelphia and London, Saunders, 1966.

2 Wood, P, Diseases of the Heart and Circulation, 3rd edn. London, Eyre and Spottiswoode, 1968.

${ }^{3}$ Oram, S, Clinical Heart Disease. London, Heinemann Medical Books, 1971.

${ }^{4}$ Cleland, W, et al, Medical and Surgical Cardiology. Oxford and Edinburgh, Blackwell, 1969.

${ }^{5}$ Logue, R B, and Sykes, C, fournal of the American Medical Association, 1952, 148, 1209.

Western Regional Cardiac and Thoracic Centre, Western Hospital, Southampton SO9 4WQ

ROGER CHAPMAN, BSC, MB, senior house officer

NEVILLE CONWAY, MB, FRCP, consultant cardiologist

\section{Imported tularaemia}

Indigenous tularaemia has not been reported in Britain though laboratory infections have occurred. ${ }^{1}$ One case of ulceroglandular tularaemia was diagnosed in a 61-year-old man who had travelled from North America. ${ }^{2}$ We report a second case imported from France in December 1974.

\section{Case report}

A much-travelled 27-year-old Englishman was making his way at night in winter through remote thorny scrubland in the foothills of the Pyrenees near Pau, when he fell down a hole. He fell among thorns, felt pain in his right index finger, and assumed that a thorn had gone through his glove. The pain disappeared, but next day his finger itched and two days later he began to feel giddy and lightheaded. His finger became more itchy and he became unusually hungry. He returned to Britain, febrile and feeling ill, and was treated initially with procaine penicillin and then ampicillin $1 \mathrm{~g}$ daily for 14 days, followed by clindamycin $300 \mathrm{mg}$ for seven days. During this time a gland enlarged in his right axilla and the site of injury on his right index finger developed a small ulcer. After treatment he became afebrile but continued to feel ill, and the ulcer and enlarged gland persisted.

Three months after he fell down the hole, the lesion on his finger was excised and the axillary gland removed. The finger lesion showed chronic inflammatory changes and the excised lymph node showed the appearance of caseating tuberculoid granulomas. Acid fast bacilli were not seen. Haemoglobin, white cell count, erythrocyte sedimentation rate, chest $x$-ray examination and $x$-ray examination of his finger were normal and Heaf test was strongly positive. Skin test with cat scratch fever extract was negative. The Pasteurella tularensis agglutination test was positive at $1 / 640$ dilution and a week later at $1 / 1280$, and two months later was still positive at $1 / 640$. Sections of the ulcer from his finger were examined after fluorescent antibody staining with $P$ tularensis conjugates. Tests with European type B antibody reagents were positive but similar tests with American type reagents were negative. By the time the diagnosis of ulceroglandular tularaemia had been made, he had recovered his normal vigour and health and his finger had healed.

\section{Discussion}

Tularaemia is a disease involving rodents, hares, rabbits, and arthropods. We think our patient probably fell on an infected animal which bit him, and the short incubation period, local ulcer with enlarged regional gland, histology of the gland, and antibodies were all typical of ulceroglandular tularaemia. 
Most human cases have been reported from North America, Scandinavia, Russia, Japan, and the continent of Europe. In Eastern. France and Germany there is a zone where human infections have been recognised ${ }^{3}$ but cases have not been reported before from the French Pyrenees, though infected rodents and hares have been found near Bordeaux. ${ }^{4}$ Our patient's illness thus extends the known geographical distribution of tularaemia, and we report the case as an example of the importation of the disease to Britain.

${ }^{1}$ Ledingham, J C G, and Fraser, F R, Quarterly fournal of Medicine, 1923-4, 17,365 .

2 Blomley, D J, and Pearson, A D, British Medical fournal, 1972, 4, 235.

3 Jusatz, H J, in Welt-Seuchen Atlas Pt I, ed E Roderwaldt, p 31. Hamburg, Falk-Verlag, 1952.

${ }^{4}$ Jusatz, H J, in Welt-Seuchen Atlas Pt II, ed E Roderwaldt, p 37. Hamburg, Falk-Verlag, 1954.

\section{Hereford Hospitals, Hereford}

J B WOOD, BM, MRCP, consultant physician

K VALTERIS, FRCPATH, consultant pathologist

R H HARDY, DM, MRCGP, senior casualty officer

Department of Bacteriology, Southampton University, Southamp-

A D PEARSON, BM, DIP BACT, senior lecturer

\section{Antibody response of infants in tropics to five doses of oral polio vaccine}

Three doses of oral polio vaccine (OPV), as currently recommended, are not sufficient for effective immunisation of infants in tropical countries owing to poor seroconversion rates. ${ }^{12}$ Consequently paralytic poliomyelitis does occur in vaccinated populations. ${ }^{3}$ The seroconversion rates of infants to five doses of OPV are reported here.

\section{Subjects, methods, and results}

All infants were aged between 6 and 51 weeks when the first dose of OPV was given, by methods described elsewhere. ${ }^{4}$ During the course of investigations the titre of OPV was repeatedly checked and found unchanged from the recommended levels. ${ }^{4}$ The interval between doses was four weeks except in a few children in whom it was five or six weeks. Blood was collected from vaccinees immediately before giving the first dose of OPV, and again four weeks after the third dose, when a fourth dose was given. A third sample of blood was collected four weeks after the fifth dose. All sera were tested for the presence and titre of neutralising antibodies at a starting dilution of $1 / 8$, against 100-300 TCID $_{50}$ of poliovirus types 1,2 , and $3 .^{4}$

A total of 78 infants were studied. Sera taken from 55 infants after the third dose of OPV were promptly tested along with their prevaccination sera. Thirty-three infants $(60 \%)$ who had already seroconverted to the three types of poliovirus, and had received a fourth dose, were not given a fifth dose as no further seroconversions were to be gained in them. The remaining 45 infants were given a fifth dose, and four weeks later 21 were found to have seroconverted to all three types. Sixteen had seroconverted to two types only, and six to one type; two infants remained seronegative to three types.

Since the assessment of seroresponse to five doses of OPV would be biased if only the 45 infants were included and the 33 excluded from analysis, all infants are considered together. Among the total of 78 infants studied, 76 (97\%) responded to one or more serotypes and $54(69 \%)$ responded to all three serotypes. The type-specific seroconversion rates are shown in the table.

\section{Discussion}

Seroresponses of infants and children to one and two doses of OPV, and of infants to three doses, have been described from this laboratory, ${ }^{2}{ }^{4}$ using similar methods (see table). Obviously there is progressive increase in the seroresponse of vaccinees after each additional dose of OPV after the first. Such a poor seroresponse in the population is due to resistance to vaccine virus "take." 5 These results indicate that this resistance is not absolute, but could be overcome, in the
Seroresponses of infants and children to one, two, three, and five doses of trivalent $O P V$

\begin{tabular}{c|c|c|c|c}
\hline \multirow{2}{*}{ No of doses of OVP } & \multicolumn{3}{|c|}{ Seroconversion rate (\%) } & \multirow{2}{*}{ Reference No } \\
\cline { 2 - 3 } & Type 1 & Type 2 & Type 3 & \\
\hline One & 19 & 61 & 30 & $(2)$ \\
Two & 35 & 78 & 48 & $(2)$ \\
Three & 69 & 90 & 76 & $(4)$ \\
Five & 83 & 96 & 82 & \\
\hline
\end{tabular}

majority, by repeated doses. Thus five doses are proportionately better than three doses. Some infants remained seronegative to one or more serotypes of poliovirus in spite of receiving five doses of OPV, including two who remained seronegative to all three types of poliovirus. These two had no evidence of immunodeficiency and were clinically normal. They illustrate that the refractoriness to infection and seroresponse may at times be profound and persistent.

On the basis of these results we recommend that the primary course of immunisation for infants in developing countries, especially in the tropics, should consist of at least five doses of OPV given at intervals of four weeks or more.

This investigation was supported by the Indian Council of Medical Research. Help from Ms P Vijayarathnam, I Suresh, and R Elangoven; Dr M Jadhav, Dr L V Devarajan, and Dr L Luther (Vellore); and Dr C W Cockburn (WHO) and Dr John Beale (Wellcome Foundation) is gratefully acknowledged. This study was included in a doctoral thesis submitted to the University of Madras.

${ }^{1}$ Drozdov, S G, and Cockburn, W C, in Proceedings of the First International Conference on Vaccines against Viral and Rickettsial Diseases of Man, p 198. Washington, DC, Pan American Health Organisation, 1967.

${ }^{2} \mathrm{John}, \mathrm{T} \mathrm{J}$, and Jayabal, P, American fournal of Epidemiology, 1972, 96, 263.

${ }^{3}$ Ratnaswamy, L, et al, Indian Pediatrics, 1973, 10, 443.

${ }^{4} \mathrm{John}, \mathrm{T} \mathrm{J}$, et al, Pediatrics, 1976, 57, 47.

5 John, T J, American fournal of Epidemiology, 1975, 102, 414

Christian Medical College and Hospital, Vellore, Tamil Nadu, India

T JACOB JOHN, MB, MRCP, professor of microbiology and chief, enterovirus laboratory

\section{Induction of labour with buccal prostaglandin $\mathbf{E}_{2}$}

The intravenous and oral routes of prostaglandin administration for labour induction have side effects - notably vomiting, diarrhoea, and uterine hypertonus. In an attempt to obviate these we decided to induce labour by administering prostaglandin by the buccal route. This technique has not been previously reported.

\section{Patients, methods, and results}

Labour was induced for obstetric reasons in 24 women at term. Immediately after low amniotomy prostaglandin $\mathrm{E}_{2}$ tablets were placed in the buccal space between the cheek and the gum above the upper molars. The $0.5 \mathrm{mg}$ tablets were administered according to two schemes. The first 12 subjects received a fixed dose of $0.5 \mathrm{mg}$ every 30 minutes and the remaining 12 an incremental dose that was titrated according to the uterine responsethat is, $0.5 \mathrm{mg}, 0.5 \mathrm{mg}, 1.00 \mathrm{mg}, 1.00 \mathrm{mg}, 2.00 \mathrm{mg}, 2.00 \mathrm{mg}$ every 30 minutes. A maximum dose of $2.00 \mathrm{mg}$ (four tablets) half-hourly was given. Induction was considered successful if $5-\mathrm{cm}$ dilatation of the cervix or delivery was achieved within 12 hours.

In the fixed-dose group 11 patients were successfully induced, as were 10 of the 12 on incremental doses. The table shows the various points chosen for comparing the progress of labour. ${ }^{1}$ Shorter mean times occurred in the incremental group. The mean induction-to-delivery times according to parity and cervical state are less in the incremental group, being most defined in primiparous patients with unripe cervices. Six patients vomited and in one treatment had to be temporarily interrupted. Two cases developed diarrhoea. All the infants were born in good biological condition. Two developed mild jaundice. 